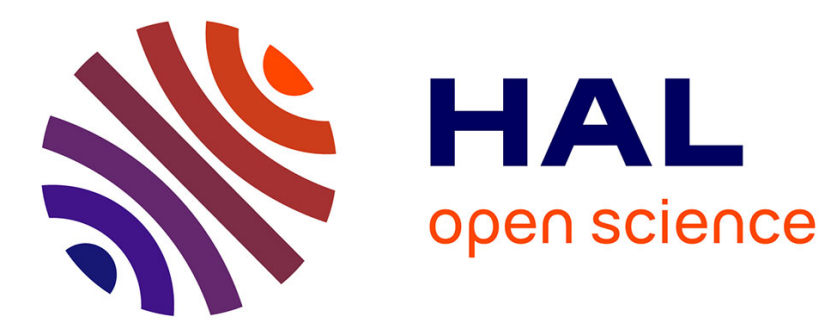

\title{
Self-Relevant Threatening Messages Promote Vigilance Toward Coping Information: Evidence of Positive Processing at Attentional Level
}

\author{
Jérôme Blondé, Fabien Girandola
}

\section{- To cite this version:}

Jérôme Blondé, Fabien Girandola. Self-Relevant Threatening Messages Promote Vigilance Toward Coping Information: Evidence of Positive Processing at Attentional Level. Social Cognition, 2018, 36 (4), pp.411-441. 10.1521/soco.2018.36.4.411 . hal-02074254

\section{HAL Id: hal-02074254 \\ https://hal-amu.archives-ouvertes.fr/hal-02074254}

Submitted on 20 Mar 2019

HAL is a multi-disciplinary open access archive for the deposit and dissemination of scientific research documents, whether they are published or not. The documents may come from teaching and research institutions in France or abroad, or from public or private research centers.
L'archive ouverte pluridisciplinaire HAL, est destinée au dépôt et à la diffusion de documents scientifiques de niveau recherche, publiés ou non, émanant des établissements d'enseignement et de recherche français ou étrangers, des laboratoires publics ou privés. 


\title{
SELF-RELEVANT THREATENING MESSAGES PROMOTE VIGILANCE TOWARD COPING INFORMATION: EVIDENCE OF POSITIVE PROCESSING AT ATTENTIONAL LEVEL
}

Jérôme Blondé and Fabien Girandola

Aix-Marseille Université

\begin{abstract}
Research has widely established that self-relevant threatening messages are effective persuasive strategies. However, very little is known about attentional processes underlying their beneficial effects. In the present research, we hypothesized that the exposure to threatening messages is likely to engage people in attentional vigilance toward coping information. Three studies examined and found support for this prediction. By using an emotional Stroop task, Study 1 revealed that, among participants high in vulnerability, those exposed to a high-threatening message reported vigilant processing of coping information. Study 2 replicated these findings by employing a dot-probe task. Study 3 demonstrated, however, that such processing depends on how much coping information is effective at protecting from the threat. Theoretical and practical implications of these findings are discussed.
\end{abstract}

Keywords: threatening messages, attention, coping information

Threatening messages are persuasion strategies that use threatening information (e.g., smoking kills, drunk-driving increases fatal crashes) in the aim of encouraging specific audiences to accept action recommendations (e.g., stop smoking, using condoms). To date, these messages have been widely used as communication techniques in health education and promotion, regarding various topics such as road safety (e.g., Carey, McDermott, \& Sarma, 2013), sexual risk-taking

\footnotetext{
This research was supported by a doctoral grant awarded to the first author from the French Ministry of Higher Education and Research.

Correspondence concerning this article should be addressed to Jérôme Blondé or Fabien Girandola, Aix-Marseille Université, Laboratoire de Psychologie Sociale, 29, avenue Robert Schuman, 13621, Aixen-Provence, France; E-mail: Jerome.blonde@gmail.com or Fabien.girandola@univ-amu.fr. 
behaviors (e.g., Slavin, Batrouney, \& Murphy, 2007; Terblanche-Smit \& Terblanche, 2011), consumption of tobacco (e.g., Ferguson \& Phau, 2013; Manyiwa \& Brennan, 2012), alcohol (e.g., Agrawal \& Duhacheck, 2010; Lee \& Shin, 2011), or drugs (e.g., Zimmerman et al., 2014). As an illustration, public health policies, in a large number of countries throughout the world (e.g., Australia, Belgium, Canada, France, New-Zealand, United Kingdom), have taken the decision of including frightening pictorial warning labels (PWLs) on cigarette packages as a strategy to encourage smoking cessation and dissuade young people to start smoking (WHO, 2003; for a meta-analysis, see Noar et al., 2016). The key assumption behind the use of threatening messages is that presenting high-threatening information, for example through vivid materials (e.g., punchy words, shocking pictures), would raise respondents' awareness of their current risky behaviors and motivation to execute recommended precautionary measures.

For more than 60 years, considerable efforts have been made to examine the validity of such an assumption (for reviews, see Ruiter, Abraham, \& Kok, 2001; Shen \& Dillard, 2014). Taken as a whole, research has provided strong empirical evidence demonstrating the effectiveness of threatening communications. Beyond a myriad of experimental studies (for recent examples, see Bailey, Wang, \& Kaiser, 2018; Blondé \& Girandola, 2017, 2018; De Vos, Crouch, Quester, \& Ilicic, 2017; Dillard, Li, \& Huang, 2017; Kang \& Lin, 2015), numerous meta-analyses have established that depicting strong threats (vs. low threats) significantly increases message acceptance, and especially among people who feel vulnerable to the threat (e.g., DeHoog, Stroebe, \& deWit, 2007; Floyd, Prentice-Dunn, \& Rogers, 2000; Milne, Sheeran, \& Orbell, 2000; Tannenbaum et al., 2015; Witte \& Allen, 2000). For example, the meta-analysis of Tannenbaum et al. (2015), which has screened more than 240 independent studies, clearly showed that using threatening information exerts a positive influence in aligning attitudes, intentions, and behaviors with message recommendations.

Although the effectiveness of threatening messages in instigating changes is now well established, yet very little is known about cognitive processes that underlie their beneficial effects. In the present research, we specifically focused on attentional processes and proposed to test the hypothesis that high-threatening messages are likely to stimulate a vigilant processing style toward coping information (i.e., information relating to the actions recommendations). Across three experiments, this work was designed to investigate such a prediction by evaluating attention allocation toward coping information after people being exposed to a high versus low-threatening message. Furthermore, the moderating role of vulnerability to the threat- the extent to which the occurrence of the threat is perceived as plausible to affect people personally-and recommendation efficacy-the extent to which the recommendation is perceived as effective at protecting against the threat-were also taken into consideration and explored. 


\section{THE PROCESSING OF THREATENING COMMUNICATIONS}

Drawing on the Parallel Process Model (Leventhal, 1970, 1971), the stress theory of Lazarus and Folkman (1984), and the Stage Model of Fear-Arousing Communications (Das, deWit, \& Stroebe, 2003; DeHoog, Stroebe, \& deWit, 2005, 2007, 2008), it can be argued that the exposure to threatening communications give rise to two main mechanisms: the processing of threatening information and processing of coping information. Both mechanisms can emerge in parallel but serve two different motivational functions.

The processing of threatening information is an emotion-focused mechanism whose purpose is to control and regulate the emotionally negative consequences elicited by the perception of the threat (e.g., fear, stress, anxiety). For this purpose, threatening information has been shown to be processed in a biased and defensive fashion (e.g., Block \& Williams, 2002; Brown \& Locker, 2009; Brown \& Smith, 2007; Croyle, Sun, \& Hart, 1997; Kunda, 1989; Liberman \& Chaiken, 1992). More specifically, an increasing number of works have demonstrated that, when exposed to personally relevant health messages, people are likely to report attentional avoidance of threatening information (e.g., Brown \& Richardson, 2012; Kessels, Ruiter, \& Jansma, 2010; Kessels, Ruiter, Wouters, \& Jansma, 2014; Maynard et al., 2014; Nielsen \& Shapiro, 2009; Stothart, Maynard, Lavis, \& Munafo, 2016). Refraining from allocating attentional resources to the processing of information that is viewed to be personally threatening functions thus as a defensive means to downsize negative emotional side effects provoked by the message. Similarly, research on self-affirmation has provided further support for such an avoidant processing style in response to health-risk communications (e.g., Kessels, Harris, Ruiter, \& Klein, 2016; Klein \& Harris, 2009; van Koningsbruggen, Das, \& RoskosEwoldsen, 2009).

Contrasting with the processing of threatening information, the processing of coping information refers to a problem-focused mechanism. It is driven by the motivation to identify solutions to counteract the threat and reach safety and protection. Indeed, when people encounter threatening situations, they strive for keeping negative emotions that such situations can engender in check, but also for protecting themselves by searching for every means that could fully eliminate the occurrence of the threat (Rogers, 1983; Witte, 1992). Any action recommendations conveyed in the message will thus be taken into consideration and appraised in terms of whether they are personally applicable and really effective at suppressing threat-related cognitions. As a result, the processing of coping information under high-threatening conditions has been proposed to be positive in the sense that coping information is likely to be inspected in ways that could satisfy people's need for protection and help engage with suggested behaviors (Das et al., 2003; DeHoog et al., 2005, 2008). For example, DeHoog and her colleagues (2008) have observed, in two studies, that people, after receiving messages depicting severe threats to which they experience high degrees of vulnerability, engaged in increased posi- 
tive elaboration of recommendation-related information, compared with other less threatening conditions. The more people feel they are under high threat, the more they elaborate on coping information so that they could ensure suggested behaviors are applicable and helpful to them. The ultimate consequence of this is that the overall acceptance and performance of message recommendations are likely to be facilitated, thereby accounting for the extensively evidenced effectiveness of threatening communications.

However, while a wealth of works have been devoted to exploring the processing of threat-related information, investigations aimed at assessing the processing of coping information are scarce, despite its clear implications for message acceptance. Besides, the hypothesis that high-threatening messages might produce positive processing of coping information cruelly lacks empirical support. Accordingly, the main goal of the current research was to examine how threatening messages affect the way people attend to coping information at the level of early stage perceptual processing.

\section{ATTENTIONAL VIGILANCE OF COPING INFORMATION}

How could positive processing of coping information be characterized at the attentional level? In the present research, we hypothesized that, when confronted with high-threatening messages (vs. low-threatening messages), people would be likely to engage in attentional vigilance to coping information (i.e., vigilance refers to a sustained and preferential allocation of attention toward one or several specific stimuli of one's environment). Indeed, given the fundamental need for seeking protection means in response to threatening stimuli, one might expect that information fulfilling such a need fully captures people's attentional resources. Thus, we posed the hypothesis that the positive processing of coping information translates into an increased attention to coping information. That being said, we expected this to occur only when personal vulnerability to the threat is high. When vulnerability is low, threatening information should produce no impact on attention, whether it is low or high. In cases where self-relevance to the threat is high, attention is thus preferentially focused on protective stimuli, while aversive stimuli are avoided.

It is worth noting that this prediction is consistent with some prior evidence showing that experiencing threatening situations causes heightened accessibility and vigilance to problem-solving information or other situationally relevant stimuli (see Jonas et al., 2014). In the field of research on social exclusion and ostracism for instance, DeWall, Maner, and Rouby (2009) have shown that people who are facing the threat of social exclusion, compared with people who did not, detected more quickly and paid more attention to smiling faces, which represent sources of social acceptance and protection (see also Xu et al., 2016). Of more direct relevance for our research, we also found support in one study conducted by Kessels and Ruiter (2012). In this study, researchers tested smokers' attentional reactions to PWLs by using eye-tracking technology. Interestingly, their findings have brought 
evidence that smokers (vs. non-smokers) instructed to look at threatening PWLs spent more time looking at coping information (i.e., information providing help for quitting smoking) than threatening information (i.e., information related to tobacco-induced risks). According to the authors, such a differential in eye movement patterns has reflected an attentional preference for coping information over threatening information. However, although this study has offered useful knowledge, we believe that it needs to be replicated and further considered with respect to two particular issues. First, their findings are not indicative of the nature of the attentional mechanisms that may arise in the processing of coping information, notably because attention allocation was measured based on a comparison with threatening information. As such, it is unclear as to whether there was a presence of vigilance or avoidance. Increased time staring at coping information could suggest that smokers' attention was merely more focused on coping information than on threatening information or, conversely, that they diverted more of their attention away from threatening information than from coping information. Second, another issue in the Kessels and Ruiter study is that the crucial role of recommendation efficacy has been overlooked. In our opinion, it is an important gap that needs to be bridged since this variable clearly has the potential to affect the processing of coping information.

\section{THE MODERATING ROLE OF RECOMMENDATION EFFICACY}

Recommendation efficacy can be defined as the perceived capacity of suggested problem-solving strategies to fully protect from the threat's negative consequences. According to the relevant literature, recommendation efficacy has been established as a key construct in the receptiveness of threatening messages (Rogers, 1983; Rogers \& Prentice-Dunn, 1997; Witte, 1992). Evidence has largely shown that incorporating effective recommendations (e.g., quitting smoking), relative to noneffective recommendations (e.g., smoking light cigarettes), into high-threatening messages results in greater conformity (e.g., Carey \& Sarma, 2016; Eppright, Hunt, Tanner, \& Franke, 2002; Lewis, Watson, \& White, 2010; Smalec \& Klingle, 2000; Stephenson \& Witte, 1998; Will, Sabo, \& Porter, 2009; Witte, 1994; for meta-analytic evidence, see Peters, Ruiter, \& Kok, 2013; Witte \& Allen, 2000). Indeed, when confronted with high self-relevant threats, people are vigorously motivated to ensure their protection, but the extent to which the proposed protective measures will be adopted is conditioned by how convincing the messages are that such measures will work. If recommended responses are of low-efficacy, people are predisposed to reject them (or at least to report a reduced acceptance), or consider some other protection means, based on their personal knowledge. However, if solutions exist that can efficiently avert dangers, applying recommendations is sufficient to eliminate the threat and provide a strong feeling of protection. The chances of acceptance are thus higher.

Based on these premises, we hypothesized that attentional vigilance is contingent upon the extent to which suggested recommendations are perceived as effec- 
tive in limiting the occurrence of threats. Because the processing of coping information is motivated by the desire of finding efficient protection measures, people are expected to focus their attention on coping information when perceived as highly protective only. Conversely, when recommendations are perceived as poor at protecting against threat-related consequences, we expected coping information not to attract people's attention.

As a result, contributions of our research were manifold. First, by using various experimental paradigms, we sought to provide one of the first systematic investigations on the attentional processing of coping information in response to threatening messages. Second, instead of assessing how much attentional resources are allocated to the processing of coping information relative to threatening information, we aimed to identify the specific nature of the attentional process that comes into play in the processing of coping information, taken separately from threatening information. Third, we also examined whether such a process could depend on the perceived efficacy of action recommendations.

\section{OVERVIEW OF THE PRESENT RESEARCH}

We tested our predictions by conducting three studies. Studies 1 and 2 were designed to explore attention allocation toward coping information and tested the hypothesis that high-threatening messages provoke more vigilance than lowthreatening messages. Furthermore, vulnerability to the threat was manipulated. We expected that the pattern of attentional vigilance would appear when vulnerability is at its highest. Otherwise, messages have no meaningful impact for people, no matter how threatening they are. Study 3 aimed to examine the moderating role of recommendation efficacy. Although it does not represent the main purpose of this work, we also measured attentional processing of threatening information and anticipated, as prior research has shown, increases of avoidance in the most threatening condition. Overall, participants were provided with several promotion-health messages that portrayed information about health threats and how to cope with them. Then, they were instructed to perform an experimental task measuring attention allocation. We decided to use an emotional Stroop task in Study 1 (Myers \& McKenna, 1996; Watts, McKenna, Sharrock, \& Trezise, 1986) and a dotprobe task in Studies 2 and 3 (MacLeod, Mathews, \& Tata, 1986).

In all studies, hypotheses were tested in the context of nutrition behaviors, namely the use of sodas and energizing drinks in Study 1, and of sugary foods (e.g., cakes, candies, sweets, etc.) in Studies 2 and 3. Although it is still mostly ignored by mass media, nutrition involves major public health issues due, for example, to the noxious consequences of sugar on diabetes, eating disorders, obesity, and dental hygiene (see Lustig, Schmidt, \& Brindis, 2012). Nutrition behaviors have received growing attention in research during recent decades, especially regarding the study of attentional biases toward food-related stimuli (e.g., Freijy, Mullan, \& Sharpe, 2014; Kemps, Tiggemann, \& Hollitt, 2014). Nevertheless, very few stud- 
ies have examined attentional reactions to nutrition-related persuasive messages (e.g., Gerend \& Maner, 2011; Wagner, Howland, \& Mann, 2015). Accordingly, we created such messages focusing on health consequences of drinking sodas and energizing drinks and of eating sugary foods that were accompanied by either low- or high-threatening description of risks and different information about vulnerability and protection.

We determined the required sample sizes for each of our three studies by using a power analysis with $\mathrm{G}^{*}$ Power. Based on an estimated effect size of $f=0.33$ (corresponding to $\eta_{p}^{2}=0.10$, which is the average effect size that we observed in relevant studies; e.g., DeHoog et al., 2005, 2008; Kessels \& Ruiter, 2012) and a desired statistical power of 0.80 , we established that we needed a minimum of 73 participants for each study (knowing that all studies included the same experimental design). Before launching these, we thus decided to stop recruiting participants when they were $73+10$, although, for practical reasons, some additional participants were still included. Also, we reported all manipulations, measures, and data exclusions in the article.

\section{STUDY 1}

Study 1 aimed to provide a first examination of attention allocation toward coping information and test the hypothesis of an increased attention. In addition, we verified whether attentional avoidance of threatening information could also emerge. To do so, we asked participants to read a health-related message that varied the threat (i.e., the degree with which risk-related information is displayed as threatening) and vulnerability to the threat (i.e., the degree of personal susceptibility to the threat). After reading the message, attention was measured through the completion of an emotional Stroop task that consisted of asking participants to report, on a computer keyboard, the color of words that were written either in red, green, or blue, whose content was either related with threatening or coping information, or with no links with the message. Based on the original Stroop task (Stroop, 1935), the emotional Stroop task indeed enables the identification of attentional mechanisms that operate when people deal with threatening cues (vs. non-threatening cues). This has been widely used in the investigation of attentional biases caused by anxiety, phobia, or addictions (e.g., Becker, Rinck, Margraf, \& Roth, 2001; Boyer \& Dickerson, 2003; Dresler, Mériau, Heekeren, \& van der Meer, 2009; Kramer \& Goldman, 2003; Mogg \& Bradley, 2002).

\section{METHOD}

Participants and Design. One hundred thirteen undergraduate students were recruited and participated in this experiment for course credits. However, we excluded the responses of 11 of them due to suspicions regarding the manipulation of vulnerability (i.e., participants had not believed the information relating to vul- 
nerability and understood that this was included for experimental purposes) and technical issues (i.e., computer crashes in completing the task) when running the task. ${ }^{1}$ Our final sample size included thus 102 participants $\left(M_{\text {Age }}=19.33, S D_{\text {Age }}=\right.$ 1.89 ; from 17 to 28 years old; 85 women), who were tested individually and randomly assigned to one of the four conditions of a 2 (vulnerability: low vs. high) $\times$ 2 (threat: low vs. high) between-subject factorial design.

Procedure and Materials. After being greeted into the lab, participants were first asked to read a health message on risks of drinking sodas or energizing drinks (that we made up). Based on existing health advertising campaigns, the message consisted of a three-page booklet divided into three parts. The first part was about a (fictitious) scientific study evidencing a powerful correlation between the consumption of sodas and energizing drinks and risk of esophageal cancers. To manipulate vulnerability (low vs. high), participants were given details about who are specifically concerned by this risk (for a similar procedure, see Ruiter, Verplanken, De Cremer, \& Kok, 2004). More specifically, they were told that the (fictitious) study showed that the consumption of sodas and energizing drinks caused $42 \%$ (vs. $2 \%$ ) of esophageal cancers and that investigated participants were French students (i.e., the same population as the one we targeted in our study; vs. 40-year-old Spanish people) who were used to drinking four to five sodas per day (i.e., which can be perceived as heavy use; vs. one to two). This manipulation was pretested and reached expected differences. The second part of the booklet described the threat (i.e., risks of esophageal cancer). As a way to oppose a low- versus highthreatening message, we manipulated how vivid information was depicted in the message (i.e., the degree with which information is presented as clear and concrete; for some precedents, see Blondé \& Girandola, 2018; Witte, 1994). In the lowthreatening message, participants were provided with an abstract and difficult text that specified the stages of cancer development, including technical wording only. In the high-threatening message, similar information was given, but written with a more concrete and accessible language, accompanied by a brief testimonial from a doctor about how patients feel the stages of cancer development. Prior to the experiment, both texts were pretested and checked to be successful in inducing distinct levels of threat vividness. Texts were designed to be of equal length and content. The last part proposed an action recommendation to protect against the threat. We suggested that participants should "drink more water," which was chosen, based on a pilot study in which several recommendations were tested, due to its high-perceived applicability and efficacy to protect. Once the message was read, participants were asked to respond to some questions that checked the manipulations, as well as participants' age and sex. Then, the experimenter presented the task and provided corresponding instructions. Note that participants were told nothing about why they were asked to read the message or complete the task, neither whether these two were related to each other. Finally, participants were debriefed and thanked for their participation. Each session lasted 30 minutes on average.

1. Across conditions, participant exclusions were distributed as following: Low Vulnerability/ Threat: $n=1(3.57 \%)$; Low Vulnerability/High Threat: $n=4(14.81 \%)$; High Vulnerability/Low Threat: $n=2(6.90 \%) ;$ High Vulnerability/Threat: $n=4(13.79 \%)$. 
The Experimental Task. The emotional Stroop task was set up following MacLeod's instructions (2005). Each trial began with the presentation of a fixation cross for $500 \mathrm{~ms}$ in the middle of the computer screen, followed by a word that was displayed until a response was given. Each word appeared in red, green, and blue on a black computer screen. Participants had to indicate, as quickly and accurately as possible, the color of each word by pressing a corresponding key on a keyboard, while ignoring its semantic content. Words were either target words or control words. Target words were either related to coping (e.g., "water," "tap") or threatening information (e.g., "cancer," "tumor"), with 3 words each. Control words were unrelated to the message but varied in terms of valence (i.e., positive, negative, neutral), ${ }^{2}$ with 6 words of each valence. We selected these words on the basis of the French word databank developed by Bonin et al. (2003). In total, 27 words were displayed in each of the three colors and the whole sequence was repeated twice in a random order (MacLeod, 2005). The task comprised thus a total of 144 trials. Prior to the experiment, participants responded to a training block of 10 words, unrelated to the message. The experimenter stayed with participants during the whole training session and checked that instructions were correctly understood. Longer reaction times (RTs) to report the color of target words than that of control words indicated the presence of avoidant processing, whereas faster RTs to target words than to control words signaled vigilant processing (Hermans, Vansteenwegen, \& Eelen, 1999).

\section{RESULTS}

Manipulation Checks. We checked the level of threat by assessing how vividly the threat was perceived. Four items were used (e.g., "When you were reading the message, had you a clear picture in your mind of what esophageal cancer is?"; $\alpha$ $=.95$ ). Responses were reported on 7-point rating scales. Results showed that participants rated the threat as less vivid in the low-threatening message $(M=4.11$, $S D=1.43)$ than in the high-threatening message $(M=5.61, S D=1.32), F(1,100)=$ $30.27, p<.001, \eta_{p}{ }^{2}=.23$. Also, we checked vulnerability with two items (e.g., "Personally, are you likely to have esophageal cancer because of your consumption of sodas or energizing drinks?"; $r=.85$ ). As expected, participants in the condition of low vulnerability perceived themselves as less vulnerable $(M=2.40, S D=1.64)$ than participants in the condition of high vulnerability $(M=3.08, S D=1.70), F(1$, 100) $=4.19, p=.043, \eta_{p}{ }^{2}=.04$.

Preliminary Analyses. First, we excluded color-naming erroneous responses from the data set $(1.37 \% ; M=2.31, S D=2.06)$ and RTs below $200 \mathrm{~ms}$ and above 1200 $\mathrm{ms}(0.59 \%)$. We checked that none of independent variables affected neither error rates nor outlier data (all $F \mathrm{~s}<2$ with $p \mathrm{~s}>.14$ ). Then, we computed a reverse trans-

2. Valence of control words was varied as a means to control its possible effects on responses to target words, as well as to check whether such responses are due to their valence or content. Because target words have specific valence, it might indeed be suspected that RTs are indicative of how people respond to positive or negative words, rather than threat-or coping-related words. To rule out this possibility, we reasoned that if responses to target words are affected by their valence, then they should differ depending on the valence of control words. Thus, we performed additional analyses where control words were distinguished according to their respective valence and compared with targets words. Corresponding analyses are reported in the results section. 
TABLE 1. Means (and SDs) of Reaction Times (RTs) and Attentional-Bias Scores (ABSs) as a Function of Threat and Vulnerability

\begin{tabular}{lcccccc}
\hline & \multicolumn{2}{c}{ Low Vulnerability } & & \multicolumn{2}{c}{ High Vulnerability } \\
\cline { 2 - 3 } \cline { 5 - 6 } \cline { 5 - 6 } & Low Threat $(\boldsymbol{n}=27)$ & High Threat $(\boldsymbol{n}=23)$ & & Low Threat $(\boldsymbol{n}=27)$ & High Threat $(\boldsymbol{n}=\mathbf{2 5})$ \\
\hline RT Threat & $596.92(93.59)$ & $599.58(104.42)$ & & $607.66(103.75)$ & $619.72(112.79)$ \\
RT Coping & $590.26(76.82)$ & $598.51(94.54)$ & & $605.68(100.36)$ & $607.67(104.82)$ \\
RT Control & $592.59(78.87)$ & $603.34(98.19)$ & & $600.75(98.92)$ & $628.70(106.55)$ \\
ABS Threat & $-4.34(29.15)$ & $3.76(23.85)$ & & $-6.91(27.59)$ & $8.97(32.35)$ \\
ABS & $2.32(24.49)$ & $4.83(24.77)$ & & $-4.93(29.67)$ & $21.03(29.06)$ \\
$\quad$ Coping & & & & & \\
\hline
\end{tabular}

Note. Means are presented untransformed for ease of interpreting.

formation $(1 / x)$ on each RT mean to conform to normalization rules and reduce skewness of the distribution (see Osborne, 2002). Finally, we checked whether the

AU: Correct as is?

Au: What does "ET" mean throughout? $\rightarrow$

valence of control words affected RTs to target words (in addition, effects of IVs were also considered). No effects emerged, whether for threat-related words (all $F \mathrm{~s}<2$ with $p \mathrm{~s}>.21$ ) or for coping-related words (all $F \mathrm{~s}<3$ with $p \mathrm{~s}>.08$ ), thereby indicating that responses to target words did not reflect any preferences due to their valence.

Attentional Scores. We calculated attentional scores by subtracting RTs for target words from RTs for control words (see Hester, Dixon, \& Garavan, 2006). Note that control words, even though of different valence, were all aggregated in the calculation of our indexes. Positive scores indicated vigilant processing, while negative scores meant avoidant processing. To test our hypothesis, we ran two 2 (vulnerability: low vs. high) $\times 2$ (threat: low vs. high) between-subject ANOVAs, with both scores for threat-related and coping-related words as dependent variables. Apart from findings of ANOVAs, it is worth noting that we also decided on the presence of vigilant or avoidant processing depending on how significantly the scores differed from 0 . Means and standard deviations of RTs and scores are displayed in Table 1. Score for Threat-Related Words. Results indicated a main effect of threat, $F(1,100)=4.20, p=.043, \eta_{p}^{2}=.04$. However, neither a main effect of vulnerability, $F(1,100)=0.05, p=.822$, nor an interaction effect, $F(1,98)=0.44, p=.507$, were found.

Score for Coping-Related Words. The analysis of variance yielded a main effect of threat, $F(1,100)=6.97, p=.010, \eta_{p}{ }^{2}=.07$, but no main effect of vulnerability, $F(1$, $100)=0.69, p=.409$. More importantly, the analysis revealed a significant interaction, $F(1,98)=4.74, p=.032, \eta_{p}{ }^{2}=.05$ (see Figure 1). In the condition of high vulnerability, participants exhibited a higher score when the threat was high $(M=21.03$, $E T=29.06)$ rather than low $(M=-4.83, E T=24.77), F(1,98)=11.86, p=.001, \eta_{p}{ }^{2}=$ .11. No effects of threat were found when vulnerability was low, $F(1,98)=0.11, p$ $=.746$. In addition, in the condition of high threat and high vulnerability, the score significantly differed from $0, t(24)=3.62, p=.001, d=1.48,95 \% \mathrm{CI}=[9.03,33.02]$, and not in the three other conditions (all $t \mathrm{~s}<2$ with $p \mathrm{~s}>.36$ ). 


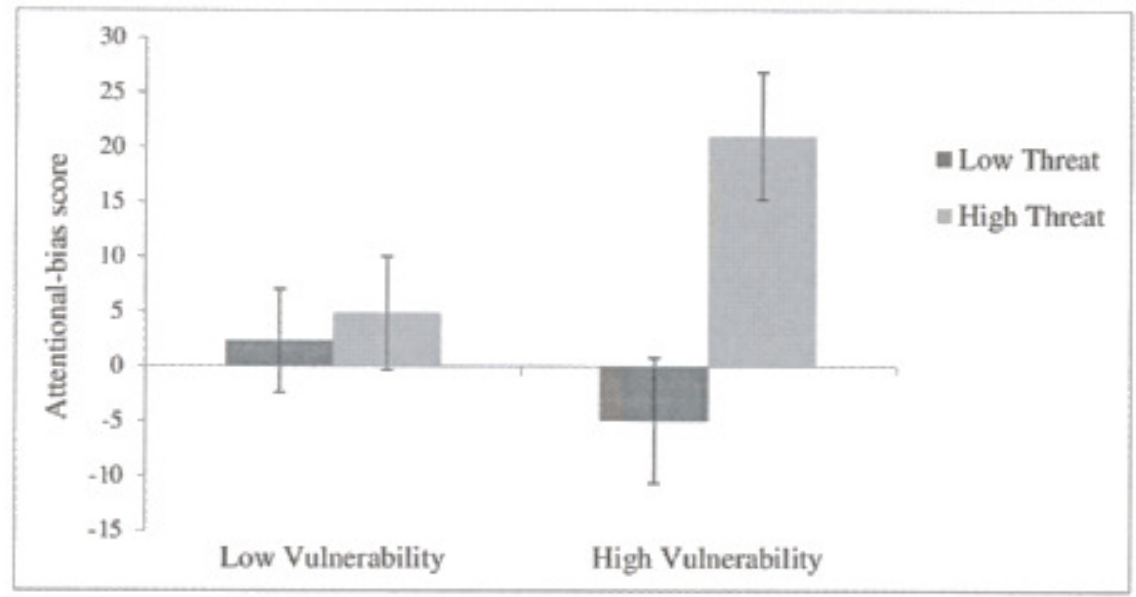

FIGURE 1. Attentional-bias score for coping-related words as a function of vulnerability and threat. Note. Error bars represent standard errors.

Comparison Between Threat- and Coping-Related Scores. Finally, in line with Kessels and Ruiter (2012), we also compared both scores as a function of our experimental conditions. More specifically, we run a 2 (threat: low vs. high) $\times 2$ (vulnerability: low vs. high) $\times 2$ (type of score: threat-related vs. coping-related) repeated measures ANOVA with the last variable as a within-subject factor. Unfortunately, results indicated neither main effects nor interactive effects (three-way interaction was nonsignificant), $F(1,98)=1.35, p=.249$. This means that attention allocation did not differ between threat-related and coping-related words.

\section{DISCUSSION}

As hypothesized, data revealed that high-threatening messages promoted attentional vigilance toward coping information, but only when people felt vulnerable to the threat. When they did not experience such vulnerability, threatening messages had no effect on the processing of coping information, no matter how threatening the threat was depicted. Surprisingly, the avoidance of threatening information did not emerge.

Such findings are promising but have to be replicated to gain in validity. Furthermore, although it is one of the most used tasks to assess attentional processes toward threatening stimuli (Williams, Mathews, \& MacLeod, 1996; Yiend, 2010), the emotional Stroop task has recently been called into question for difficulties in terms of interpretation (Cisler \& Koster, 2010). Indeed, an increase of RTs could indicate a difficulty to respond due to the anxiety induced by the exposure to threatening stimuli, as well as an attentional preference for it (Algom, Chaju, \& Lev, 2004). In addition, the distinction between avoidant and vigilant processes resulted from a comparison from control words and was not derived from the visual 
attention allocation (MacLeod et al., 1986; Posner, 1988). To address these limitations, we re-tested our hypotheses in Study 2 by using another experimental task.

\section{STUDY 2}

This study was designed to replicate Study 1 and test the hypothesis of vigilance by using a dot-probe task (MacLeod et al., 1986; Mogg \& Bradley, 1998). Drawing on the well-recognized finding that people are faster to detect signals when popping up in the same visual area where attention is already focused (Posner, Snyder, \& Davidson, 1980), the merits of such paradigm is to offer an alternative measurement of attention that bridges the gaps of the emotional Stroop task by assessing attention from the visual attentional allocation. Like the emotional Stroop task, this paradigm also constitutes a frequently used method in studying the appraisal of threatening stimuli among individuals suffering from anxiety, addictions, or phobias (e.g., Chen, Ehlers, Clark, \& Mansell, 2002; Mogg, Philippot, \& Bradley, 2004; Salemink, van den Hout, \& Kindt, 2007).

\section{METHOD}

Participants and Design. Eighty-six undergraduate students were recruited and participated in this experiment for course credits. However, similar to Study 1, we excluded the responses of 11 of them due to suspicions regarding the way we manipulated vulnerability and technical issues when running the task. ${ }^{3}$ Our final sample size included thus a total of 75 participants $\left(M_{A g e}=19.48, S D_{A g e}=1.33\right.$; from 17 to 23 years old; 63 women), who were tested individually and randomly assigned to one of the four conditions of a 2 (vulnerability: low vs. high) $\times 2$ (threat: low vs. high) between-subject factorial design.

Procedure and Materials. The overall procedure and materials were identical to those in Study 1, except that we used a new health topic, namely the risk of eating sugary foods (e.g., candies, cakes) and, accordingly, made appropriate changes. The messages outlined how the use of sugary foods can increase the risk of infarction. Perceived vulnerability to the threat was manipulated through the indication that the risk of infarction was higher for people between ages 16 and 26 and lower for people 55 and over (vs. the reverse in the condition of low vulnerability). We checked that all our participants were in this age bracket. This manipulation was pretested and resulted in expected differences. Similar to Study 1, the threat was manipulated by varying how vivid the portrayal of the risk was. The low-threatening message explained the biological functioning and symptoms of an infarction with abstract and technical terms, while the high-threatening message included a concrete and accessible terminology, accompanied by a brief testimonial from a person who had had an infarction. The recommendation proposed that participants should "eat more light or low-fat foods," which was selected on the basis of

3. Across conditions, participant exclusions were distributed as following: Low Vulnerability/ Threat: $n=2(9.52 \%)$; Low Vulnerability/High Threat: $n=3(13.63 \%)$; High Vulnerability/Low Threat: $n=2(9.52 \%)$; High Vulnerability/Threat: $n=5(21.74 \%)$. 
a pilot study for its high applicability and efficacy. Once the message was read and then manipulations checked, participants were invited to perform the dot-probe task, before being debriefed and thanked for their participation.

The Experimental Task. In this paradigm, participants are placed in front of a computer screen and instructed to stare at a fixation cross appearing at the center of the screen for $1000 \mathrm{~ms}$. Then, pairs of words appear, one on each side of the screen, for a very short period $\left(500 \mathrm{~ms}^{4}\right)$, one each on the left and right side of the screen. Once disappeared, a visual dot is presented at the location of one of the two previous words and remains until a response is given. Finally, participants were asked to indicate the dot's position, as quickly and accurately as possible, by pressing a corresponding button on the keyboard. Pairs of words were either experimental (i.e., neutral word was accompanied by a target word) or control (i.e., neutral word was accompanied by another neutral word). Two types of trial are of interest in the dot-probe paradigm: the congruent trials which are trials where dots appeared at the same location as target words and the incongruent trials which are those where dots appeared at the opposite location. The attentional processes (i.e., vigilance or avoidance) are inferred from the comparison between RTs to congruent and incongruent trials. Based on the premise that responding to the probe is faster when attention is already allocated to the spatial location where the dots appear, vigilance (or congruency effect) translates into faster responding to congruent trials than to incongruent trials, while it is reasoned that faster RTs to incongruent trials than congruent trials are an indication of attentional avoidance (Cisler \& Koster, 2010).

We included four target words: two were related to threatening information ("infarction," "cardiac") and two others were related to coping information ("light," "low-fat"). Also, words related to the unhealthy behavior were tested (i.e., "sugar," "cake"). 5

Neutral words were selected to be unrelated to the content of the message but varied in terms of valence (i.e., positive, negative, neutral). Contrary to Study 1 , these words were identified on the basis of a pilot study in which a set of 47 words was rated. We selected 5 positive words (e.g., "sun," "holidays"), 5 negative words (e.g., "pain," "anger"), and 5 neutral words (e.g., "jacket," "truck"). Each pair was checked to be of equivalent length and frequency in the French language. In total, the task comprised 96 trials, including 24 control trials and 72 experimental trials. In the experimental trials, there were 36 incongruent trials and 36 congruent trials. The order of trials was randomized. The dot appeared equally to the left and to the right of the screen and equally after neutral words and target words (to avoid strategic responding). Moreover, target words were presented equally to the right and to the left. Before starting, participants performed a training block of 12 trials (with words unrelated to the message).

4. This presentation time was chosen as it is one of the most prevalent, and used in studies using the dot-probe paradigm (see, for example, the recent review of van Rooijen, Ploeger, \& Kret, 2017). However, it should be bore in mind that $500 \mathrm{~ms}$ is long enough for attention to shift away and could not accurately reflect its initial orientation (Bradley, Mogg, \& Millar, 2000). During this time, it is also likely that the effect of inhibition-of-return (IOR; i.e., this refers to a delay in responding to stimuli presented at recently fixated locations) might have occurred, resulting in impaired speed and accuracy in detecting stimuli.

5. As these words yielded no differences, we do not further mention them. 
TABLE 2. Means (and SDs) of Reaction Times (RTs) and Attentional-Bias Scores (ABSs) as a Function of Threat and Vulnerability

\begin{tabular}{lcccccc}
\hline & \multicolumn{2}{c}{ Low Vulnerability } & & \multicolumn{2}{c}{ High Vulnerability } \\
\cline { 2 - 3 } & $\begin{array}{c}\text { Low Threat } \\
(\boldsymbol{n}=19)\end{array}$ & $\begin{array}{c}\text { High Threat } \\
(\boldsymbol{n}=19)\end{array}$ & & $\begin{array}{c}\text { Low Threat } \\
(\boldsymbol{n}=19)\end{array}$ & $\begin{array}{c}\text { High Threat } \\
(\boldsymbol{n}=18)\end{array}$ \\
\hline RT Threat & & & & & \\
$\quad$ Congruent & $322.26(31.55)$ & $335.10(46.64)$ & & $364.50(51.87)$ & $333.40(46.16)$ \\
$\quad$ Incongruent & $319.88(31.70)$ & $338.61(58.09)$ & & $365.65(55.21)$ & $330.49(42.02)$ \\
RT Coping & & & & & \\
$\quad$ Congruent & $327.43(37.63)$ & $333.96(48.30)$ & & $367.78(47.40)$ & $329.11(43.72)$ \\
$\quad$ Incongruent & $336.46(38.70)$ & $330.07(42.54)$ & & $362.67(49.21)$ & $343.28(49.06)$ \\
ABS Threat & $-2.38(20.40)$ & $3.51(29.96)$ & & $1.16(24.32)$ & $-2.91(26.75)$ \\
ABS Coping & $9.03(43.65)$ & $-3.89(19.02)$ & & $-5.11(28.36)$ & $14.17(26.25)$ \\
\hline
\end{tabular}

Note. Means are presented untransformed for ease of interpreting.

\section{RESULTS}

Manipulation Checks. By using the same items as those included in Study 1, we found that participants evaluated the threat as less vivid in the low-threatening message $(M=3.90, S D=1.40$, than in the high-threatening message $(M=6.16, S D$ $\left.=0.70), F(1,73)=77.06, p<.001, \eta_{v}{ }^{2}=.51\right)$. Furthermore, people who were exposed to the low-vulnerability message $(M=3.47, S D=1.44)$ reported less vulnerability than those exposed to the high-vulnerability message $(M=4.27, S D=1.30), F(1$, $73)=6.33, p=.014, \eta_{p}^{2}=.08$.

Preliminary Analyses. Similar to Study 1, erroneous responses were excluded $(0.65 \% ; M=0.63, E T=1.02)$, as well as RTs below $200 \mathrm{~ms}$ and above $1200 \mathrm{~ms}$ $(0.51 \%)$. Number of errors and outlier responses were not affected by our independent variables (all $F \mathrm{~s}<1$ with $p s>.14$ ). Then, we calculated a reverse transformation for each RT mean. Finally, we checked whether there was an impact of control words' valence (the independent variables, as well as type of trial, were also included in the analyses). We found no effects, whether for threat-related words (all $F \mathrm{~s}<1$ with $p \mathrm{~s}>.45$ ) or coping-related words (all $F \mathrm{~s}<1$ with $p \mathrm{~s}>.39$ ). We thus concluded that any effects on responses to target words could not be accounted for by their valence.

Attentional Scores. Attentional scores for both threat-related and coping-related words were calculated by subtracting RTs for congruent trials from RTs for incongruent trials (Klein \& Harris, 2009; MacLeod \& Matthews, 1988). Positive scores indicated vigilant processing, while negative scores represented avoidant processing (Mogg \& Bradley, 1999). We reported means and standard deviations of RTs and attentional scores in Table 2.

Score for Threat-Related Words. Neither main effect of threat, $F(1,73)=0.02, p$ $=.878$, nor vulnerability, $F(1,73)=0.06, p=.809$, reached statistical significance. Similarly, no interaction emerged, $F(1,71)=0.71, p=.403$.

Score for Coping-Related Words. Results revealed no main effect of threat, $F(1,73)$ $=0.20, p=.655$, and vulnerability, $F(1,73)=0.08, p=.783$, but a significant interaction effect, $F(1,71)=5.15, p=.026, \eta_{p}{ }^{2}=.07$ (see Figure 2). Among participants 


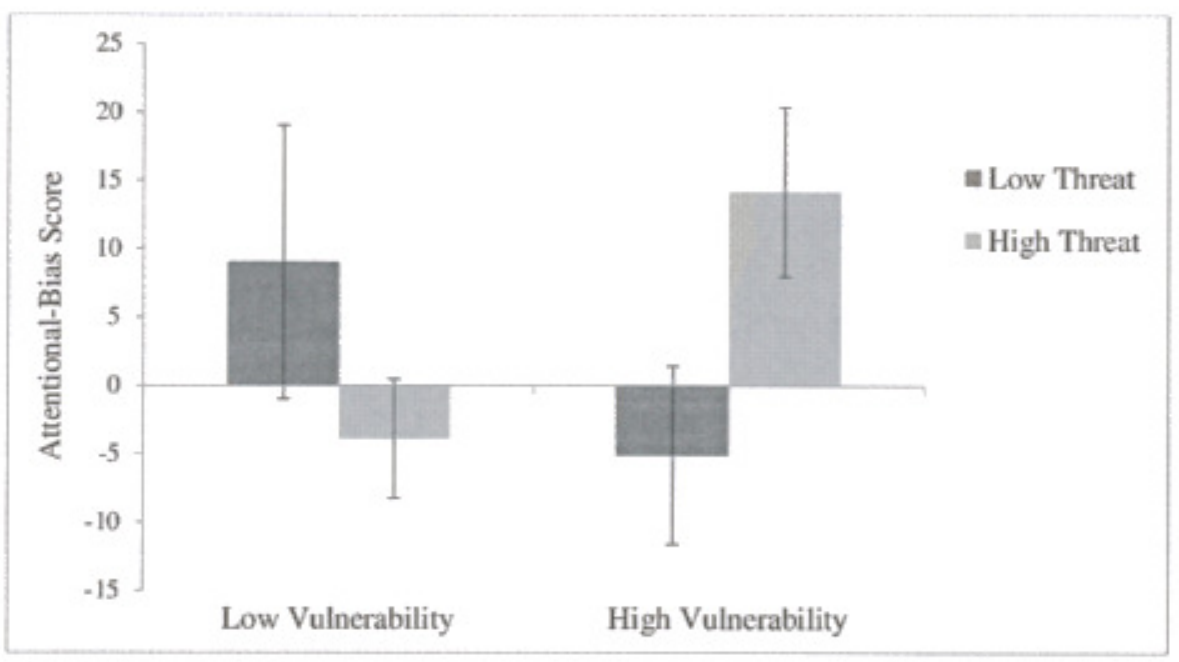

FIGURE2.Attentional-bias score for coping-related words as a function of threat and vulnerability. Note. Error bars represent standard errors.

high in vulnerability, those who were exposed to the high threat had a marginally higher score $(M=14.17, S D=26.25)$ than those who were exposed to the low threat $(M=-5.11, S D=28.36), F(1,71)=3.64, p=.060, \eta_{p}^{2}=.05$. In contrast, no differences emerged among participants low in vulnerability, $F(1,71)=1.68, p=.199$. Furthermore, the attentional score in condition of high threat and high vulnerability significantly differed from $0, t(17)=2.29, p=.035, d=1.11,95 \% \mathrm{CI}=[1.11,27.22]$. No such difference appeared in the three other conditions (all $t \mathrm{~s}<1$ with $p \mathrm{~s}>.37$ ). ${ }^{6}$

Comparison Between Threat- and Coping-Related Scores. Similar to Study 1, we performed a 2 (threat: low vs. high) $\times 2$ (vulnerability: low vs. high) $\times 2$ (type of score: threat-related vs. coping-related) repeated measures ANOVA with the last variable as a within-subject factor. Of particular importance, this analysis revealed a significant three-way interaction, $F(1,71)=5.252, p=.025, \eta_{p}{ }^{2}=.07$. To specify this interaction, we compared patterns of response between scores depending on each condition. We found a marginally significant difference in the condition of high threat/high vulnerability, $F(1,71)=3.312, p=.073, \eta^{2}=.05$, showing that people reported higher scores for coping-related words $(M=14.17, S D=26.25)$ than threat-related words $(M=-2.91, S D=26.75)$. No significant differences appeared in the three other conditions (all $F s<2, p s>.21$ ).

6. Koster, Crombez, Verschuere, and De Houwer (2004) have suggested that faster responses to congruent than incongruent trials might translate vigilance, as well as a difficulty to disengage. It is thus important to address this distinction so to specify which kind of process occurred in the condition of high threat/vulnerability. To do so, it is required to compare congruent/incongruent trials to neutral trials. Significant differences between congruent and neutral trials indicate the presence of vigilance, whereas differences between incongruent and neutral trials suggest a difficulty to disengage. The performing of such analyses revealed marginal differences between RTs to congruent trials $(M=343.28, S D=49.06)$ and those to neutral trials $(M=334.98, S D=49.86), t(17)$ $=1.93, p=.07, d=0.93,95 \% \mathrm{CI}=[-0.002,0.51]$, but no differences between incongruent and neutral trials, $t(17)<2$. Thus, the effects of messages in this condition reflect vigilance and not a difficulty to disengage. 


\section{DISCUSSION}

By using a visual dot-probe task, we replicated previous findings and, even though, once again, no effects on threatening information have been found, we showed that the exposure to high-threatening messages increased vigilant processing of coping-related information, but only when people felt vulnerable to the threat. When they did not perceive themselves as vulnerable to the threat, threatening messages had no effect on the processing of coping information.

\section{STUDY 3}

Study 3 was designed to further explore the role of recommendation efficacy on attention allocation toward coping information. Given that people strive for an efficient protection when attending coping information, we expected recommendation efficacy to mitigate its attentional processing, such that attentional vigilance should arise only when coping information can be perceived as guaranteeing strong protection against the threat. At the opposite, when of low efficacy, coping information is useless and could not help people subdue the threat, and so cannot hold people's attention. For the same reasons as exposed in previous studies, we also predicted that these effects would only occur when the message is highly threatening and of high personal relevance (i.e., a combined condition of high threat and high vulnerability). In this study, participants were provided with the same messages as those used in Study 2, but we varied the suggested recommendation so that we compared one condition including a recommendation of low efficacy with another of high efficacy. We also varied the threat as we did in Study 2 but we held high degrees of vulnerability constant in all conditions, as the previously obtained effects only occurred when vulnerability was high. Once again, we used a dot-probe task to measure attentional processing.

\section{METHOD}

Participants and Design. Eighty-eight undergraduate students were recruited and participated in this experiment for course credits. However, we excluded data of 10 participants due to suspicions regarding the manipulation of efficacy and technical issues when running the task. ${ }^{7}$ Our final sample size included thus 78 participants $\left(M_{\text {Age }}=19.35, S D_{\text {Age }}=1.44\right.$; from 17 to 25 years old; 63 women), who were tested individually and randomly assigned to one of the four conditions of a 2 (efficacy: low vs. high) $\times 2$ (threat: low vs. high) between-subject factorial design.

Procedure and Materials. The procedure and materials were the same as those we employed in Study 2. Participants were all asked to read a message including the information that we used in Study 2 for inducing high levels of vulnerability,

7. Across conditions, participant exclusions were distributed as follows: Low Threat/Efficacy: $n=$ 3(13.04\%); Low Threat/High Efficacy: $n=1$ (4.55\%); High Threat/Low Efficacy: $n=3$ (13.04\%); High Threat/Efficacy: $n=3(15 \%)$. 
Au: should this be "low efficacy" ? namely that people between the ages of 16 to 26 were the most at risk. We ensured that our participants were all of this age bracket and that perceived vulnerability was sufficiently strong $(M=3.92, S D=1.50)$. The threat was manipulated as in Study 2. To manipulate the level of recommendation efficacy, we changed the recommendation suggested in the message and used two recommendations, varying in terms of how they were able to fully avert the threat. Both recommendations were identified after conducting a pilot study in which several were tested. The two recommendations that differed the most were included, namely "eating more fruits and vegetables" for the high-efficacy condition and "eating more salted foods" for the low-efficacy condition. Both were perceived as easy to perform (in the pilot study, two questions were asked about the perceived ease of applying them). It is worth mentioning that the low-effective recommendation could, nevertheless, have been perceived as hard to believe and, consequently, messaged as of little credibility, as most people were expected to know that eating salt is unhealthy. To address this issue, we asked each participant independently, while debriefing, whether they had been puzzled and suspicious of such a recommendation while reading the message. We decided to remove from the final sample participants who explicitly expressed suspicions or doubts regarding this manipulation. Once the message was read, they were asked to respond to some questions that checked the manipulations and then to complete the experimental task.

The Experimental Task. As in Study 2, participants performed a dot-probe task. However, as the recommendations differed between the condition of low and high efficacy, we changed target words from which we assessed attentional allocation toward coping information depending on the condition participants were assigned. We used two specific words for the condition of low efficacy ("salted," "sodium") and two others for the condition of high efficacy ("fruits," "vegetables").

\section{RESULTS}

Manipulation Checks. As desired, we found that participants estimated the threat as less vivid in the low-threatening message $(M=4.07, S D=1.80)$ than in the highthreatening message $(M=6.16, S D=0.80), F(1,76)=42.21, p<.001, \eta_{p}{ }^{2}=.36$. Also, we checked recommendation efficacy by asking two questions (e.g., "I think that [the recommendation] is effective to protect myself against the risk of infarction"; $r$ $=.96)$, both reported on 7-point rating scales. Results showed that the low-efficacy recommendation $(M=3.64, S D=1.86)$ was rated as less effective than the highefficacy recommendation $(M=5.99, S D=1.23), F(1,76)=42.86, p<.001, \eta_{p}{ }^{2}=.36$.

Preliminary Analyses. Similar to previous studies, we eliminated erroneous responses from our data set $(1.12 \% ; M=0.81, S D=1.23)$. Also, RTs below $200 \mathrm{~ms}$ and above $1200 \mathrm{~ms}$ were excluded $(1.10 \%)$. Note that none of the independent variables affected either error rates or outlier data (all $F \mathrm{~s}<2$ with $p s>.19$ ). Then, a reverse transformation on each RT mean was computed. Finally, similar to Study 2, we ran additional analyses to verify whether the valence of control words would exert an influence on participants' responses. These analyses revealed no effects on both threat-related words (all $F \mathrm{~s}<2$ with $p \mathrm{~s}>.30$ ) and coping-related words (all $F s<3$ with $p s>.13$ ). Specifically, it should be noted that the interaction between valence of control words and efficacy is nonsignificant. Since coping-related target 
TABLE 3. Means (and SDs) of Reaction Times (RTs) and Attentional-Bias Scores (ABSs) as a Function of Threat and Efficacy

\begin{tabular}{lcclcc}
\hline & \multicolumn{2}{c}{ Low Threat } & & \multicolumn{2}{c}{ High Threat } \\
\cline { 2 - 3 } & $\begin{array}{c}\text { Low Efficacy } \\
(\boldsymbol{n}=\mathbf{2 0})\end{array}$ & $\begin{array}{c}\text { High Efficacy } \\
(\boldsymbol{n}=\mathbf{2 1})\end{array}$ & & $\begin{array}{c}\text { Low Efficacy } \\
(\boldsymbol{n}=\mathbf{2 0})\end{array}$ & $\begin{array}{c}\text { High Efficacy } \\
(\boldsymbol{n}=\mathbf{1 7})\end{array}$ \\
RT Threat & & & & & \\
$\quad$ Congruent & $327.20(39.55)$ & $348.82(50.59)$ & & $338.00(49.91)$ & $348.20(60.39)$ \\
$\quad$ Incongruent & $332.65(36.99)$ & $356.22(52.58)$ & & $337.25(45.91)$ & $335.61(43.21)$ \\
RT Coping & & & & & \\
$\quad$ Congruent & $333.03(38.10)$ & $350.07(53.36)$ & & $346.79(53.68)$ & $324.15(37.34)$ \\
$\quad$ Incongruent & $329.13(40.70)$ & $349.76(56.65)$ & & $335.45(46.61)$ & $336.63(38.12)$ \\
ABS Threat & $5.44(23.56)$ & $7.40(31.49)$ & & $-0.75(29.23)$ & $-12.59(33.55)$ \\
ABS Coping & $-3.91(21.28)$ & $-0.31(16.37)$ & & $-11.34(24.17)$ & $12.48(18.66)$ \\
\hline
\end{tabular}

Note. Means are presented untransformed for ease of interpreting.

words could be assumed more positive in the condition of high-efficacy than those in the condition of low-efficacy, this means that the differential of valence across target words used in the condition of low versus high efficacy had no impact on participants' RTs. Possible differences would not be the result of their possible varying valence.

Attentional-Bias Scores. We calculated the same scores and performed the same analyses as those in Study 2. Means and standard deviations of RTs and attentional scores are reported in Table 3.

Score for Threat-Related Words. The $2 \times 2$ ANOVA revealed no main effect of threat, $F(1,74)=3.81, p=.055$, efficacy, $F(1,74)=0.54, p=.464$, as well as no interaction effect, $F(1,76)=1.06, p=.308$.

Score for Coping-Related Words. First, we found a main effect of efficacy, $F(1,76)=$ yielded a significant interaction effect, $F(1,74)=4.78, p=.032, \eta_{p}^{2}=.06$ (see Figure $3)$. In the condition of high threat, participants reported a higher score when the recommendation was of high efficacy $(M=12.48, S D=18.66)$ rather than low $(M=$ $-11.34, S D=24.17), F(1,74)=12.59, p=.001, \eta_{p}{ }^{2}=.15$. No effect of efficacy emerged when the threat was low, $F(1,74)=0.32, p \stackrel{p}{=} .573$. Besides, when the threat was high, data showed that the attentional scores significantly differed from 0 in the condition of high efficacy, $t(16)=2.76, p=.014, d=1.38,95 \% \mathrm{CI}=[2.89,22.08]]^{8}$ as well as in the condition of low efficacy, $t(19)=2.10, p=.049, d=0.96,95 \% \mathrm{CI}$ $=[0.03,22.65]$. Of importance, score is positive in the condition of high efficacy, while negative in the condition of low efficacy.

Comparison Between Threat- and Coping-Related Scores. Like in previous studies, we ran a 2 (threat: low vs. high) $\times 2$ (efficacy: low vs. high) $\times 2$ (type of score:

8. To discriminate whether this finding indicated vigilance or a difficulty to disengage, we performed identical analyses as in Study 2. We found shorter RTs to congruent $(M=324.15, S D=$ $37.34)$ than to neutral trials $(M=336.99, S D=43.19), t(16)=3.22, p=.005, d=0.32,95 \% \mathrm{CI}=[4.38$, 21.30 , but no differences emerged between incongruent and neutral trials, $t(16)<1$. The effects of high-efficacy reflected thus vigilance to coping information. 


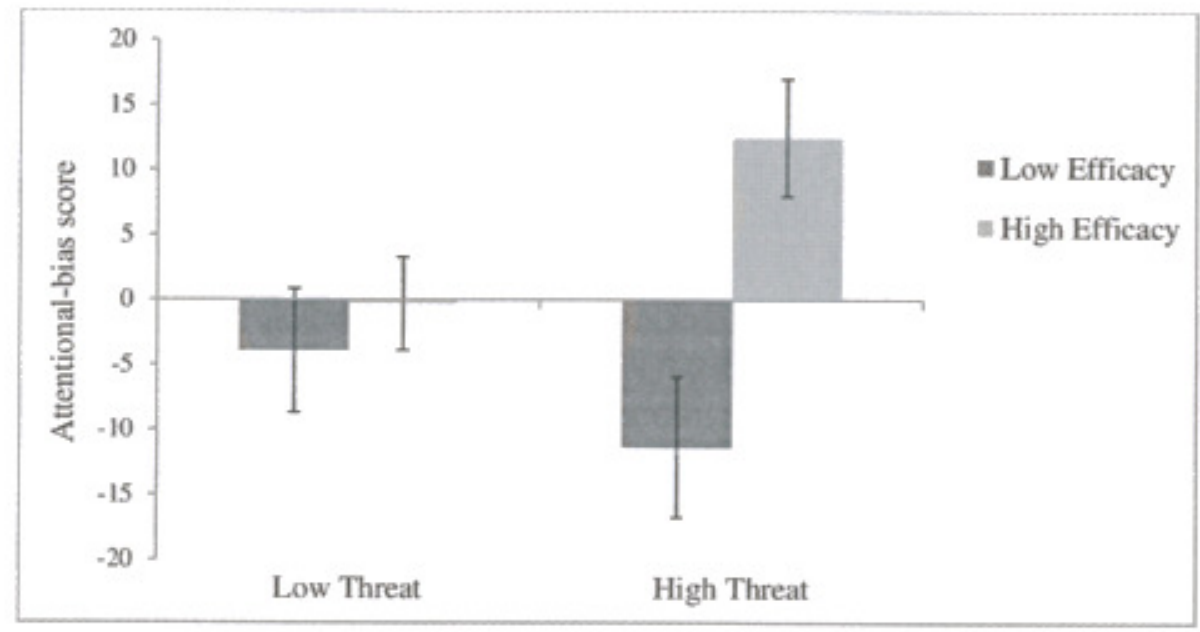

FIGURE 3. Attentional-bias score for coping-related words as a function of threat and efficacy. Note. Error bars represent standard errors.

threat-related vs. coping-related) repeated measures ANOVA with the last variable as a within-subject factor. We found a significant three-way interaction, $F(1$, $74)=4.605, p=.035, \eta_{p}{ }^{2}=.06$, revealing a higher score for coping-related words $(M=12.48, S D=18.66)$ than threat-related words $(M=-12.59, S D=33.55)$ in the condition of high threat/high efficacy, $F(1,74)=8.779, p=.004, \eta_{p}{ }^{2}=.11$. Analyses did not indicate any other significant effects in the three other conditions (all $F \mathrm{~s}<$ $2, p s>.17)$.

\section{DISCUSSION}

As hypothesized, these findings indicated that, when the message was highly threatening, the inclusion of high-effective recommendations triggered attentional vigilance toward coping information. Surprisingly, while we expected no specific processing to occur when the recommendation was not helpful at protecting from the threat, participants reported an attentional avoidance of coping information. At the opposite, when the threat was low, coping information did not receive people's attention, replicating thus findings of Studies 1 and 2.

\section{GENERAL DISCUSSION}

The present research aimed to examine how the exposure to threatening messages could affect the processing of coping information at early-stage attentional processes. Findings from the current studies provided consistent support for the hypothesis that high-threatening messages promoted more attention toward coping information, relative to low-threatening messages. Whether assessed through the emotional Stroop task or the dot-probe task, we demonstrated that such in- 
creased attention reflected attentional vigilance, that is, a preferential allocation of attentional resources toward stimuli likely to offer protection against the threat. However, Studies 1 and 2 consistently revealed that only messages embedding arguments that the threat was of high self-relevance (vs. low) ended up arousing such vigilant processing. Also, Study 3 specified that the capacity of coping information to avert dangers can modulate attention. When perceived as high efficacy, coping information received vigilance, but when perceived as low efficacy, coping information was subject to avoidance. In addition, replicating Kessels and Ruiter's findings, we also found that, when messages depicted self-relevant high-threatening information, attention was preferentially oriented toward recommendationrelated information rather than threat-related information, provided recommendation-related information pertains to action recommendations of high efficacy.

Taken as a whole, these findings illustrated the crucial notion that including threatening material in persuasive messages contributes to forming positive reactions by making people with high vulnerability direct their gaze on information that provides high protection. Following the exposure to self-relevant threatening messages, people are indeed in need of finding efficient means of protection so that attention is thoroughly focused on information likely to fulfill such need for protection. As a result, coping information draws and holds attention of people the most concerned, leading, in turn, to more elaboration and acceptance of message recommendations (DeHoog et al., 2005, 2008). That being said, of great interest to note that when coping information is of poor quality to avert dangers, people tended to process messages by allocating their attentional resources away from recommendation-related information. If coping information proves to be useless to achieve their ongoing protection goals, then people divert their attention from threatening information, as well as from coping information, probably to other stimuli likely to offer more protection in reducing the threat.

It is worthwhile to mention that, contrary to a myriad of prior studies (e.g., Brown \& Richardson, 2012; Kessels et al., 2014), our data showed no avoidant processing of threat-related information in response to high-threatening messages. However, our research is not an exception. For instance, the study of Kessels, Ruiter, and Jansma (2010), although demonstrating avoidance through the use of neuroscience methods, has indicated no effects of threatening anti-smoking messages on threat-related RTs while participants were being asked to complete a Posner cueing task. Similarly, Kessels, Harris, Ruiter, and Klein (2016) also failed to provide evidence of attentional avoidance of threatening information. Even further, people sometimes have been found to show greater attentional preferences for threatening information than for neutral information (Bradley, Field, Healy, \& Mogg, 2008; Süssenbach, Niemeier, \& Glock, 2013). Thus, although demonstrated many times, the case of avoidant processing of threatening information remains unclear. One interpretation of that null finding might be that threatening information was, in fact, the target of an objective processing. When warned of serious threats, perhaps that defensive response might not always occur. People might accept being at risk without avoiding the threatening content of conveyed information. However, care should be taken in interpreting findings as such because it is also possible that 
defensiveness toward threatening information actually occurred, but in a different form than attentional avoidance, which the dot-probe paradigm was unable to capture. Defensive strategies to deal with threatening messages are indeed manifold (for reviews, see Good \& Abraham, 2007; McQueen, Vernon, \& Swank, 2013), including threat denial, unrealistic optimism, or reactance. Thus, even though our findings did not give evidence of defensive avoidance of threatening information, the conclusion should not be drawn that such defensive processes are unlikely, as it might have arisen from the exposure to our messages, but manifested in a different manner.

\section{THEORETICAL IMPLICATIONS}

The present research has important theoretical implications. First, it offers a meaningful framework for understanding the widely documented effectiveness of threatening communications. By specifically examining the attentional mechanism behind the processing of information pertaining to the action recommendation, which has been noticed as one key component of threatening messages in past models although left unexplored, we propose a new perspective accounting for positive reactions to messages occurring at the level of explicit responses (i.e., self-reported attitude, intention, and behavior): threat-based messages prompt vulnerable people to accept and adopt advocated behaviors because they stimulate their attention to focus on corresponding protective information.

Second, since research has exclusively examined the attentional processing of threatening information and found that people are likely to engage in defensive avoidance of it, some scholars have come to the conclusion that threatening messages are counterproductive persuasion techniques, which would undermine the chances that people actually set in motion protective actions (e.g., Kessels et al., 2010; Kok, Peters, Kessels, ten' Hoor, \& Ruiter, 2017; Peters, Ruiter, \& Kok, 2014; Ruiter, Kessels, Peters, \& Kok, 2014; ten' Hoor et al., 2012). After all, it could be argued that, if threatening information is dismissed, there seems to be no reason to believe that messages would exert any influence on people's intentions to change. The less threatening information receives attention and the less people would be motivated to attend in ways to cope with them afterwards. Not surprisingly, these scholars have urged health practitioners and message designers to abandon the use of threatening messages as intervention methods for changing health behaviors (e.g., see Bartholomew, Parcel, Kok, Gottlieb, \& Fernández, 2011; Kok, Bartholomew, Parcel, Gottlieb, \& Fernandez, 2014). However, we suggest that it could be misleading to draw such a conclusion based on the sole evidence of avoidant processing toward threat-related information. Even though our findings did not give support for such processing, we can, nonetheless, contend that diverting attention away from threat-related information might not preclude people from exhibiting positive and vigilant reactions toward coping information, which, in fine, would result in more acceptance of action recommendations. Along with some recently developed perspectives (e.g., Blondé \& Girandola, 2017; Van't Riet \& Ruiter, 
2013), one can then suggest that defensive reactions and increased acceptance can co-occur in response to a threatening message. Despite the fact that the exposure to threatening communications might engage in defensively disregarding threatening parts of the message, this would not prevent people from reporting greater acceptance of recommendation, as they are also likely to express heightened sensitivity toward recommendation-related information. Hence, we believe that our findings have the potential to bring insights into reconciling and clarifying the conflicting views about the persuasiveness of threatening messages by integrating them into a single and coherent theoretical whole.

In parallel, such a theorization could also lead us to reconsider the deeply rooted assumption whereby the success of threatening messages would result from a decline of defenses and, conversely, that the failure would be caused by their emergence (see, for example, the Extended Parallel Process Model; Witte, 1992, 1998). Building on our findings and the notion that defensive reactions and acceptance could co-occur, we propose that the persuasiveness of threatening messages is the result of positive vigilant processing of coping information, whereas their rejection stems from either reduced vigilance or increased avoidance toward coping information, as suggested in Study 3. As such, the most determining and relevant clue to decide the true effects of threatening messages should be placed on how positive reactions are toward the action recommendations rather than on how defensive they are toward the threat.

Third, the current studies offer interesting pieces of evidence with respect to controversies over how efficacy could moderate the effect of the threat. Indeed, even though the role of recommendation efficacy is now largely acknowledged, research on threatening messages is debating as to whether efficacy and threat produce interactive or additive effects. The interactive perspective considers that high threats cannot produce positive effects without the combining help of high efficacy (e.g., Goodall \& Reed, 2013; Peters et al., 2013; Witte, 1998; Witte \& Allen, 2000 ), whereas the additive perspective argues that low efficacy just lowers beneficial effects of high threats (e.g., Goei et al., 2010; Popova, 2014). At the attentional level, our findings clearly corroborate and give support to the interactive perspective, as we have shown that combining high threat with low efficacy is associated with negative reactions, such that people reported to keep coping information out

Au: Should this be high-efficacy? $\rightarrow$ of their attention. Thus, we contend that high-effective recommendations are not extra but essential parts for the persuasiveness of threatening messages.

\section{PRACTICAL IMPLICATIONS}

In view of the extensive use of threatening messages as interventions in educating health-related behaviors, the present research has also a number of practical implications. Overall, our findings suggest that threatening messages are effective strategies and can be of interest for all those who seek to motivate people to engage in 
performing more adaptive behaviors, since we demonstrated that these are likely to enhance positive processing of coping information. However, the benefits of threatening messages are not unrestricted and require message makers to adhere to certain conditions. First, high perception of personal vulnerability is necessary, whether induced by targeting specific populations or by including persuasive information likely to elevate the feeling of being personally at risk (as we did in the present studies).

Second, findings of Study 3 have also underscored the importance of providing effective solutions when designing messages, as a means to focus people's attention on them. If not, the recommendations are avoided and are not likely to yield desired changes. However, such practices are not usually undertaken by message developers, who are often predisposed to believe that portraying high-threatening information is sufficient to motivate changes without combining it with clear and effective instructions (Ruiter et al., 2014). For example, when looking at current PWLs displayed on cigarette packs sold in the E.U., no recommendations were indicated other than a short statement inviting smokers to call quitting services, which can hardly help to encourage cessation (see Hoek, Gendall, Eckert, Rolls, \& Louviere, 2016; Thrasher et al., 2014). From our perspective, we urge designers to reinforce the visibility of existing solutions and ensure that these can be perceived as having high efficacy to protect. As an illustration, Canada has recently implemented, as a complement to threatening PWLs on cigarettes packages, messages promoting recommendation efficacy (i.e., benefits of quitting) and confidence in the ability of smokers to quit. Thrasher et al. (2016) were interested in the effects of such additional messages on smokers' reactions. They observed that increased reading of these gain-framed messages predicted more quitting intentions and actual smoking cessations. Accordingly, accompanying high-threats with effective coping information can be an effective lever for health actions. Nevertheless, such a perspective is still in its early stages and needs to be more implemented by message developers. However, we hope that our research, which gives evidence of the need to include effective coping information, will encourage designers and public health policy makers to keep going in this direction.

\section{LIMITATIONS AND FUTURE PERSPECTIVES}

The present studies had some limitations that need to be considered but that could, however, pave the way for useful future research. One pertains the way we measured attention. Although both the emotional Stroop task and the dot-probe task have been shown to be valuable paradigms, one problem is that they give an indirect assessment of information processing and do not identify the location of attention during the exposure to the message. As such, the lack of results regarding the processing of threat-related information could derive from that issue. When attentional processes were evaluated, participants had already read recommenda- 
tions. Perhaps the perceptions of these would have attenuated the expression of defenses toward the threat and would have pushed people to concentrate on the recommendations more than the aversive stimuli. Also, the time delay between the exposure of the message and the completion of the task might have had an effect on participants' reactions. High elaboration (i.e., people might have generated many thoughts toward the message) occurring during that time could have alleviated defensive responses, as evidence has already shown (e.g., Block \& Williams, 2002; Keller \& Block, 1996). Futures studies might consider using a technique like eye-tracking for example, which encompasses real-time recordings of attention allocation.

Another limitation is that the study did not account for the role of emotion. However, negative emotions (e.g., fear, arousal, anxiety) have been found to act on the relationship between the perception of threat and subsequent appraisals (e.g., Dillard, Li, Meczkowski, Yang, \& Shen, 2017; So, Kuang, \& Cho, 2016; Witte, 1992) and perhaps that such emotions could have constituted antecedents of why people focused their attention on protective information. Future experiments should thus include measures of negative emotions and test their potential power to explain underlying attentional processes. Also, our studies were only focused on outcomes related to attention allocation, but did not include self-report measures of acceptance (i.e., measures of explicit attitude, behavioral intention, or behavior). Although we assumed that heightened vigilance to suggested solutions would encourage their adoption, especially when these are of high efficacy, there is indeed nothing to prove it. Accordingly, new studies are needed to warrant such a prediction.

\section{CONCLUDING REMARKS}

To conclude, the converging evidence presented in the present research illuminated that threatening messages can promote positive attentional processing of coping information. That way, we have offered crucial contributions to research on threatening messages. On a broader level, the most important of them is to give support to the idea that the processing of threatening messages encompasses the processing of threatening information and that of coping information, and that both imply different motivations and are likely to affect attention in different ways. Accordingly, we encourage forthcoming theoretical accounts not to give such a distinction a miss when attempting to build comprehensive understanding of the effects of threatening messages and, in parallel, to develop further research exploring the under-examined processing of coping information. 


\section{REFERENCES}

Agrawal, N., \& Duhachek, A. (2010). Emotional compatibility and the effectiveness of anti-drinking messages: A defensive processing perspective on shame and guilt. Journal of Marketing Research, 47, 263-273. https://doi.org/10.1509/ jmkr.47.2.263

Algom, D., Chajut, E., \& Lev, S. (2004). A rational look at the emotional Stroop phenomenon: Generic slowdown, not a Stroop effect. Journal of Experimental Psychology: General, 133, 323-338. https:// doi.org/10.1037/0096-3445.133.3.323

Bailey, R. L., Wang, T., \& Kaiser, C. K. (2018). Clash of the primary motivations: Motivated processing of emotionally experienced content in fear appeals about obesity prevention. Health Communication, 33(2), 111-121. https://doi.org/10.1080 /10410236.2016.1250186

Bartholomew, L. K., Parcel, G. S., Kok, G., Gottlieb, N. H., \& Fernández, M. E. (2011). Planning health promotion programs: An intervention mapping approach. San Francisco, CA: Jossey-Bass.

Becker, E. S., Rinck, M., Margraf, J., \& Roth, W. T. (2001). The emotional Stroop effect in anxiety disorders: General emotionality or disorder specificity. Journal of Anxiety Disorders, 15, 147-159. https://doi. org/10.1016/S0887-6185(01)00055-X

Block, L. G., \& Williams, P. (2002). Undoing the effects of seizing and freezing: Decreasing defensive processing of personally relevant messages. Journal of Applied Social Psychology, 32, 803-833. https://doi. org/10.1111/j.1559-1816.2002.tb00243

Blondé, J., \& Girandola, F. (2017). When defensive reactions contribute to the acceptance of fear-arousing communications. Current Psychology. https://doi. org /10.1007/s12144-017-9590-z

Blondé, J., \& Girandola, F. (2018). Are vivid (vs. pallid) threats persuasive? Examining the effects of threat vividness in health communications. Basic and Applied Social Psychology, 40(1), 36-48. https://doi.org /10.1080/01973533.2017.1412969

Bonin, P., Méot, A., Aubert, L., Malardier, N., Niedenthal, P., \& Capelle-Toczek, M. C. (2003). Normes de concrétude de valeur d'imagerie, de fréquence subjective et de valence émotionnelle pour
866 mots. L'Année Psychologique, 103(4), 655-694. https://doi.org/10.3406/ psy. 2003.29658

Boyer, M., \& Dickerson, M. (2003). Attentional bias and addictive behaviour: Automaticity in a gambling specific modified Stroop task. Addiction, 98, 61-70. https: / / doi.org/10.1046/j.1360-0443.2003.00219

Bradley, B. P., Field, M., Healy, H., \& Mogg, K. (2008). Do the affective properties of smoking-related cues influence attentional and approach biases in cigarette smokers? Journal of Psychopharmacology, 22(7), 737-745. https://doi. org $/ 10.1177 / 0269881107083844$

Bradley, B. P., Mogg, K., \& Millar, N. H. (2000). Covert and overt orienting of attention to emotional faces in anxiety. Cognition and Emotion, 14(6), 789-808. https://doi. org $/ 10.1080 / 02699930050156636$

Brown, S. L., \& Locker, E. (2009). Defensive responses to an emotive antialcohol message. Psychology and Health, 24, 517-528. https://doi. org $/ 10.1080 / 08870440801911130$

Brown, S. L., \& Richardson, M. (2012). The effect of distressing imagery on attention to and persuasiveness of an anti-alcohol message: A gazetracking approach. Health Education and Behavior, 39, 8-17. https://doi. org $/ 10.1177 / 1090198111404411$

Brown, S. L., \& Smith, E. Z. (2007). The inhibitory effect of a distressing antismoking message on risk perceptions in smokers. Psychology and Health, 22(3), 255-268. https://doi. org $/ 10.1080 / 14768320600843127$

Carey, R. N., McDermott, D. T., \& Sarma, K. M. (2013). The impact of threat appeals on fear arousal and driver behavior: A meta-analysis of experimental research 1990-2011. PLoS ONE, 8(5), 628621. https://doi.org/10.1371/journal. pone. 0062821

Carey, R. N., \& Sarma, K. M. (2016). Threat appeals in health communication: Messages that elicit fear and enhance perceived efficacy positively impact on young male drivers. BMC Public Health, 16, 645. https://doi.org/10.1186/s12889016-3227-2 
Chen, Y. P., Ehlers, A., Clark, D. M., \& Mansell, W. (2002). Patients with generalized social phobia direct their attention away from faces. Behaviour Research and Therapy, 40(6), 677-687. https://doi. org/10.1016/S0005-7967(01)00086-9

Cisler, J. M., \& Koster, E. H. (2010). Mechanisms of attentional biases toward threat in anxiety disorders: An integrative review. Clinical Psychology Review, 30(2), 203-216. https://doi.org/10.1016/j. cpr.2009.11.003

Croyle, R. T., Sun, Y. C., \& Hart, M. (1997). Processing risk factor information: Defensive biases in health-related judgments and memory. In K. J. Petrie \& J. A. Weinman (Eds.), Perceptions of health and illness: Current research and applications (pp. 267-290). Amsterdam: Harwood Academic

Das, E., deWit, J. B. F., \& Stroebe, W. (2003). Fear appeals motivate acceptance of action recommendations. Personality and Social Psychology Bulletin, 29, 650-664. https:// doi.org/10.1177/0146167203029005009

DeHoog, N., Stroebe, W., \& deWit, J. B. F. (2005). The impact of fear appeals on the processing and acceptance of action recommendations. Personality and Social Psychology Bulletin, 31, 24-33. https:// doi.org/10.1177/0146167204271321

DeHoog, N., Stroebe, W., \& deWit, J. B. F. (2007). The impact of vulnerability to and severity of a health risk on processing and acceptance of fear-arousing communications: A meta-analysis. Review of General Psychology, 11, 258-285. https://doi. org $/ 10.1037 / 1089-2680.11 .3 .258$

DeHoog, N., Stroebe, W., \& deWit, J. B. F. (2008). The processing of fear-arousing communications: How biased processing leads to persuasion. Social Influence, 3, 84-113. https://doi. org $/ 10.1080 / 15534510802185836$

De Vos, S., Crouch, R. C., Quester, P. G., \& Ilicic, J. (2017). Examining the effectiveness of fear appeals in prompting help-seeking: The case of at-risk gamblers. Psychology and Marketing, 34(6), 648-660. https:// doi.org/10.1002/mar.21012

DeWall, C. N., Maner, J. K., \& Rouby, D. A. (2009). Social exclusion and early-stage interpersonal perception: Selective attention to sign of acceptance. Journal of Personality and Social Psychology, 96(4),
729-741. https://doi.org/10.1037/ a0014634

Dillard, J. P., Li, R., \& Huang, Y. (2017). Threat appeals: The fear-persuasion relationship is linear and curvilinear. Health Communication, 32(11), 1358-1367. https://doi.org/10.1080/10410236.201 6.1220345

Dillard, J. P., Li, R., Meczkowski, E., Yang, C., \& Shen, L. (2016). Fear responses to threat appeals: Functional form, methodological considerations, and correspondence between static and dynamic data. Communication Research, 44(7), 1-22. https:// doi.org/10.1177/0093650216631097

Dresler, T., Mériau, K., Heekeren, H. R., \& van der Meer, E. (2009). Emotional Stroop task: Effect of word arousal and subject anxiety on emotional interference. Psychological Research, 73(3), 364-371. https://doi.org/10.1007/s00426-0080154-6

Eppright, D. R., Hunt, J. B., Tanner, J. B., \& Franke, G. R. (2002). Fear, coping and information: A pilot study on motivating a healthy response. Health Marketing Quarterly, 20(1), 51-73. https://doi.org/ 10.1111/j.1539-6924.2010.01544

Ferguson, G., \& Phau, L. Y. (2013). Adolescent and young adult response to fear appeals in anti-smoking messages. Young Consumers, 14(2), 155-166. https://doi. org/10.1108/17473611311325555

Floyd, D. L., Prentice-Dunn, S., \& Rogers, R. W. (2000). A meta-analysis of research on Protection Motivation Theory. Journal of Applied Social Psychology, 30, 407-429. https://doi. org /10.1111/j.1559-1816.2000.tb02323

Freijy, T., Mullan, B., \& Sharpe, L. (2014). Foodrelated attentional bias: Word versus pictorial stimuli and the importance of stimuli calorific value in the dot-probe task. Appetite, 83, 202-208. https://doi. org/10.1016/j.appet.2014.08.037

Gerend, M. A., \& Maner, J. K. (2011). Fear, anger, fruits, and veggies: Interactive effects of emotion and message framing on health behavior. Health Psychology, 30(4), 420423. https://doi.org/10.1037/a0021981

Goei, R., Boyson, A. R., Lyon-Call, S. K., Schott, C., Wasilevich, E., \& Cannarile, S. (2010). An examination of EPPM predictions when threat is perceived externally: An asthma intervention 
with school workers. Health Communication, 25(4), 333-344. https://doi. org $/ 10.1080 / 10410231003775164$

Good, A., \& Abraham, C. (2007), Measuring defensive responses to threatening messages: A meta-analysis of measures. Health Psychology Review, 1, 208-229. https:// doi.org $/ 10.1080 / 17437190802280889$

Goodall, C. E., \& Reed, P. (2013). Threat and efficacy uncertainty in news coverage about bed bugs as unique predictors of information seeking and avoidance: An extension of the EPPM. Health Communication, 28(1), 63-71. https://doi.org/10.1 080/10410236.2012.689096

Hermans, D., Vansteenwegen, D., \& Eelen, P. (1999). Eye movement registration as a continuous index of attention deployment: Data from a group of spider anxious students. Cognition and Emotion, 13, 419-434. https://doi. org $/ 10.1080 / 026999399379249$

Hester, R., Dixon, V., \& Garavan, H. (2006). A consistent attentional bias for drugrelated material in active cocaine users across word and picture versions of the emotional Stroop task. Drug and Alcohol Dependence, 81(3), 251-257. https://doi. org /10.1017/S1461145714000522

Hoek, J., Gendall, P., Eckert, C., Rolls, K., \& Louviere, J. (2016). A comparison of on-pack quitline information formats. Tobacco Control, 25, 211-217. https://doi.org/10.1136/tobaccocontrol-2014-051820

Jonas, E., McGregor, I., Klackl, J., Agroskin, D., Fritsche, I., Holbrook, C., et al. (2014). Threat and defense: From anxiety to approach. In J. M. Olson \& M. P. Zanna (Eds.), Adoances in experimental social psychology (Vol. 49, pp. 219-286). San Diego, CA: Academic Press.

Kang, J., \& Lin, C. A. (2015). Effects of message framing and visual-fear appeals on smoker responses to antismoking ads. Journal of Health Communication, 20(6), 647-655. https://doi.org/10.1080/1081 0730.2015.1012242

Keller, P. A., \& Block, L. G. (1996). Increasing the persuasiveness of fear appeals: The effect of arousal and elaboration. Journal of Consumer Research, 22(4), 448-459. https://doi.org/10.1086/209461

Kemps, E., Tiggemann, M., \& Hollitt, S. (2014). Biased attentional processing of food cues and modification in obese individuals. Health Psychology, 33(11), 1391-1401. https://doi.org/10.1037/ hea0000069

Kessels, L. T., Harris, P. R., Ruiter, R. A. C., \& Klein, W. M. P. (2016). Attentional effects of self-affirmation in response to graphic antismoking images. Health Psychology, 35(8), 891-897, https://doi. org $/ 10.103 /$ hea0000366

Kessels, L. T., \& Ruiter, R. A. C. (2012). Eye movement responses to health messages on cigarette packages. BMC Public Health, 12, 352. https://doi. org /10.1186/1471-2458-12-352

Kessels, L. T., Ruiter, R. A. C., \& Jansma, B. M. (2010). Increased attention but more efficient disengagement: Neuroscientific evidence for defensive processing of threatening health information. Health Psychology, 29, 346-354. https://doi. org $/ 10.1037 / \mathrm{a} 0019372$

Kessels, L. T., Ruiter, R. A. C., Wouters, L., \& Jansma, B. M. (2014). Neuroscientific evidence for defensive avoidance of fear appeals. International Journal of Psychology, 49, 80-88. https://doi.org/10.1002/ ijop.12036

Klein, W. M. P., \& Harris, P. R. (2009). Selfaffirmation enhances attentional bias toward threatening components of a persuasive message. Psychological Science, 20, 1463-1467. https://doi.org/10. 1111/j.1467-9280.2009.02467

Kok, G., Bartholomew, L. K., Parcel, G. S., Gottlieb, N. S., \& Fernandez, M. E. (2014). Finding-theory and evidence-based alternatives to fear appeals: Intervention mapping. International Journal of Psychology, 49(2), 98-107. https://doi. org/10.1002/ijop.12001

Kok, G., Peters, G. J. Y., Kessels, L. T. E., ten Hoor, G. A., \& Ruiter, R. A. C. (2017). Ignoring theory and misinterpreting evidence: The false belief in fear appeals. Health Psychology Review, 12(2), 111-125. https://doi.org/10.1080/17437199.201 7.1415767

Koster, E. H. W., Crombez, G., Verschuere, B., \& De Houwer, J. (2004). Selective attention to threat in the dot probe paradigm: Differentiating vigilance and difficulty to disengage. Behaviour Research and Therapy, 42, 1183-1192. https://doi. org $/ 10.1016 /$ j.brat.2003.08.001 
Kramer, D. A., \& Goldman, M. S. (2003). Using a modified Stroop task to implicitly discern the cognitive organization of alcohol expectancies. Journal of Abnormal Psychology, 112, 171-175. https://doi. org /10.1037/0021-843X.112.1.171

Kunda, Z. (1987). Motivated inference: Selfserving generation and evaluation of causal theories. Journal of Personality and Social Psychology, 53, 636-647. https:// doi.org/10.1037/0022-3514.53.4.636

Lazarus, R. S., \& Folkman, S. (1984). Stress, appraisal, and coping. New York: Springer.

Lee, M. J., \& Shin, M. (2011). Fear versus humor: College risk takers' physiological, cognitive and emotional responses to anti-alcohol abuse PSAs. Journal of Psychology: Interdisciplinary and Applied, 145(2), 73-92. https://doi.org/10.1080/ 00223980.2010 .532519

Leventhal, H. (1970). Findings and theory in the study of fear communications. In L. Berkowitz (Ed.), Advances in experimental social psychology (Vol. 5, pp. 119-186). New York: Academic.

Leventhal, H. (1971). Fear appeals and persuasion: The differentiation of a motivational construct. American Journal of Public Health, 61, 1208-1224. https://doi. org/10.2105/AJPH.61.6.1208

Lewis, I. M., Watson, B., \& White, K. M. (2010). Response efficacy: The key to minimizing rejection and maximizing acceptance of emotion-based anti-speeding messages. Accident Analysis and Prevention, 42(2), 459-467. https://doi. org/10.1016/j.aap.2009.09.008

Liberman, A., \& Chaiken, S. (1992). Defensive processing of personal relevant health messages. Personality and Social Psychology Bulletin, 18, 669-679. https://doi. org $/ 10.1177 / 0146167292186002$

Lustig, R. H., Schmidt, L. A., \& Brindis, C. D. (2012). Public health: The toxic truth about sugar. Nature, 482, 27-29. https:// doi.org/10.1038/482027a

MacLeod, C. M. (2005). The Stroop task in cognitive research. In $\mathrm{A}$. Wenzel \& $\mathrm{D}$. C. Rubin (Eds.), Cognitive methods and their application to clinical research (pp. 17-40). Washington, DC: American Psychological Association.

MacLeod, C. M., \& Mathews, A. (1988). Anxiety and the allocation of attention to threat. Quarterly Journal of Experimen- tal Psychology: Human Experimental Psychology, 40, 653-670. https://doi. org / $10.1080 / 14640748808402292$

Macleod, C. M., Mathews, A., \& Tata, P. (1986). Attentional bias in emotional disorders. Journal of Abnormal Psychology, 95(1), 15-20. https://doi.org/10.1037/0021843X.95.1.15

Manyiwa, S., \& Brennan, R. (2012). Fear appeals in anti-smoking advertising: How important is self-efficacy? Journal of Marketing Management, 28, 1419-1437. https:// doi.org/10.1080/0267257X.2012.71509

Maynard, O. M., Attwood, A., O'Brien, L., Brooks, S., Hedge, C., Leonards, U., \& Munafo, M. R. (2014). Avoidance of cigarette pack health warnings among regular cigarette smokers. Drug and Alcohol Dependence, 136(1), 170-174. https://doi. org/10.1016/j.drugalcdep.2014.01.001

McQueen, A., Vernon, S. W., \& Swank, P. R. (2013). Construct definition and scale development for defensive information processing: An application to colorectal cancer screening. Health Psychology, 32, 190-202. https://doi.org/10.1037/ a0027311

Milne, S., Sheeran, P., \& Orbell, S. (2000). Prediction and intervention in healthrelated behavior: A meta-analytic review of Protection Motivation Theory. Journal of Applied Social Psychology, 30(1), 106-143. https://doi. org/10.1111/j.1559-1816.2000.tb02308

Mogg, K., \& Bradley, B. P. (1998). A cognitive-motivational model of anxiety. Behaviour Research and Therapy, 36, 809848. https://doi.org/10.1016/S00057967(98)00063-1

Mogg, K., \& Bradley, B. P. (1999). Some methodological issues in assessing attentional biases for threatening faces in anxiety: A replication study using a modified version of the probe detection task. Behaviour Research and Therapy, 37, 595604. https://doi.org/10.1016/S00057967(98)00158-2

Mogg, K., \& Bradley, B. P. (2002). Selective processing of smoking-related cues in smokers: Manipulation of deprivation level and comparison of three measures of processing bias. Journal of Psychopharmacology, 16(4), 385-392. https://doi. org $/ 10.1177 / 026988110201600416$ 
Mogg, K., Philippot, P., \& Bradley, B. P. (2004). Selective attention to angry faces in clinical social phobia. Journal of Abnormal Psychology, 113(1), 160-165. https://doi. org/10.1037/0021-843X.113.1.160

Myers, L. B., \& McKenna, F. P. (1996). The colour naming of socially threatening words. Personality and Individual Differences, 20, 801-803. https://doi. org/10.1016/0191-8869(96)00019-0

Nielsen, J., \& Shapiro, S. (2009). Coping with fear through suppression and avoidance of threatening information. Journal of Experimental Psychology: Applied, 15, 258274. https://doi.org/10.1037/a0017018

Noar, S. M., Hall, M. G., Francis, D. B., Ribisl, K. M., Pepper, J. K., \& Brewer, N. T. (2016). Pictorial cigarette pack warnings: A meta-analysis of experimental studies. Tobacco Control, 25(3), 341-354. https://doi.org/10.1136/tobaccocontrol-2014-051978

Osborne, J. (2002). Notes on the use of data transformations. Practical Assessment, Research and Evaluation, 8(6), 11.

Peters, G. J. Y., Ruiter, R. A. C., \& Kok, G. (2013). Threatening communication: A critical re-analysis and a revised metaanalytic test of fear appeal theory. Health Psychology Review, 7, 8-31. https://doi. org $/ 10.1080 / 17437199.2012 .703527$

Peters, G. J., Ruiter, R. A. C., \& Kok, G. (2014). Threatening communication: A qualitative study of fear appeal effectiveness beliefs among intervention developers, policymakers, politicians, scientists, and advertising professionals. International Journal of Psychology, 49(2), 71-79. https://doi.org/10.1002/ijop.12000

Popova, L. (2014). Scaring the snus out of smokers: Testing effects of fear, threat, and efficacy on smokers' acceptance of novel smokeless tobacco products. Health Communication, 29(9), 924-936. https://doi.org/10.1080/10410236.201 3.824063

Posner, M. J. (1988). Structures and functions of selective attention. In T. Boll \& B. Bryant (Eds.), Master lectures in clinical neuropsychology (pp. 173-202). Washington, DC: American Psychology Association.

Posner, M. J., Snyder, C. R., \& Davidson, B. J. (1980). Attention and the detection of signals. Journal of Experimental Psy- chology, 109(2), 160-174. https://doi. org/0.1037/0096-3445.109.2.160

Rogers, R. W. (1983). Cognitive and physiological processes in fear appeals and attitude change: A revised theory of protection motivation. In J. T. Cacioppo \& R. E. Petty (Eds.), Social psychophysiology: A sourcebook (pp. 153-176). New York: Guilford.

Rogers, R. W., \& Prentice-Dunn, S. (1997). Protection motivation theory. In D. Gochman (Ed.), Handbook of health behavior research: Vol. 1. Determinants of health behavior. Personal and social (pp. 113-132). New York: Plenum.

Ruiter, R. A. C., Abraham, C., \& Kok, G. (2001). Scary warnings and rational precautions: A review of the psychology of fear appeals. Psychology and Health, 16, 613-630. https://doi. org/10.1080/08870440108405863

Ruiter, R. A. C., Kessels, L. T. E., Peters, G. J. Y., \& Kok, G. (2014). Sixty years of fear appeal research: Current state of the evidence. International Journal of Psycholo$g y, 49,63-70$. https://doi.org/10.1002/ ijop.12042

Ruiter, R. A. C., Verplanken, B., De Cremer, D., \& Kok, G. (2004). Danger and fear control in response to fear appeals: The role of need for cognition. Basic and Applied Social Psychology, 26, 13-24. https://doi. org $/ 10.1207 /$ s15324834basp2601_2

Salemink, E., van den Hout, M. A., \& Kindt, M. (2007). Selective attention and threat: Quick orienting versus slow disengagement and two versions of the dot probe task. Behaviour Research and Therapy, 45, 607-615. https://doi.org/10.1016/j. brat.2006.04.004

Shen, L., \& Dillard, J. P. (2014). Threat, fear, and persuasion: Review and critique of questions about functional form. Review of Communication Research, 2(1), 94-114. https://doi.org/10.12840

Sherman, D. A., \& Cohen, G. L. (2002). Accepting threatening information: Self-affirmation and the reduction of defensive biases. Current Directions in Psychological Science, 11, 119-123. https://doi. org/10.1111/1467-8721.00182

Sherman, D. A., \& Cohen, G. L. (2006). The psychology of self-defense: Self-affirmation theory. In M. P. Zanna (Ed.), Advances in experimental social psychology (Vol. 38 , 
pp. 183-242). San Diego, CA: Academic Press.

Slavin, S., Batrouney, C., \& Murphy, D. (2007). Fear appeals and treatment side-effects: Aneffectivecombination for HIV prevention? AIDS Care, 19(1), 130-137. https:// doi.org /10.1080/09540120600866473

Smalec, J. L., \& Klingle, R. S. (2000). Bulimia interventions via interpersonal influence: The role of threat and efficacy in persuading bulimics to seek help. Journal of Behavioral Medicine, 23(1), 37-57. https:// doi.org/10.1023/A:1005468220077

So, J., Kuang, K., \& Cho, H. (2016). Reexamining fear appeal models from cognitive appraisal theory and functional emotion theory perspectives. Communication Monographs, 83(1), 120-144. https://doi.org /10.1080/03637751.2015.1044257

Stephenson, M., \& Witte, K. (1998). Fear, threat, and perceptions of efficacy from frightening skin cancer messages. Public Health Review, 26, 147-174.

Stothart, G., Maynard, O., Lavis, R., \& Munafo, M. (2016). Neural correlates of cigarette health warning avoidance among smokers. Drug and Alcohol Dependence, 161, 155-162. https://doi.org/10.1016/j.drugalcdep.2016.01.025

Stroop, J. R. (1935). Studies of inference in serial verbal reactions. Journal of Experimental Psychology, 18(6), 643-662. https:// doi.org $/ 10.1037 / \mathrm{h} 0054651$

Sïssenbach, P., Niemeier, S., \& Glock, S. (2013). Effects of and attention to graphic warning labels on cigarette packages. Psychology and Health, 28, 1192-1206. https:// doi.org/ 10.1080/08870446.2013.799161

Tannenbaum, M. B., Helper, J., Zimmerman, R. S., Saul L., Jacobs, S., Wilson, K., \& Albarracin, D. (2015). Appealing to fear: A meta-analysis of fear appeal effectiveness and theories. Psychological Bulletin, 141(6), 1178-1204. https://doi. org $/ 10.1037 / a 0039729$

ten'Hoor, G., Peters, G. J., Kalagi, J., deGroot, L., Grootjans, K., Huschens, A., et al. (2012). Reactions to threatening health messages. BMC Public Health, 12(1011), 1-8. https://doi.org/10.1186/14712458-12-1011

Terblanche-Smit, M., \& Terblanche, N. S. (2011). HIV/AIDS marketing communication and the role of fear, efficacy, and cultural characteristics in promoting social change. Journal of Public Affairs, 11(4), 279-286. https://doi.org/10.1002/ pa.420

Thrasher, J. F., Osman, A., Moodie, C., Hammond, D., Bansal-Travers, M., Cummings, K.M., et al. (2014). Promoting cessation resources through cigarette package warning labels: A longitudinal survey with adult smokers in Canada, Australia and Mexico. Tobacco Control, 24, 23-31. https://doi.org/10.1136/tobaccocontrol-2014-051589

Thrasher, J. F., Swayampakala, K., Cummings, K. M., Hammond, D., Anshari, D., Krugman, D. M., \& Hardin, J. W. (2016). Cigarette package inserts can promote efficacy beliefs and sustained smoking cessation attempts: A longitudinal assessment of an innovative policy in Canada. Preventive Medicine, 88, 59-65. https:// doi.org/10.1016/j.ypmed.2016.03.006

van Koningsbruggen, G. M., Das, E., \& Roskos-Ewoldsen, D. R. (2009). How self-affirmation reduces defensive processing of threatening health information: Evidence at implicit level. Health Psychology, 28, 563-568. https://doi. org/10.1037/a0015610

van Rooijen, R., Ploeger, A., \& Kret, M. E. (2017). The dot-probe task to measure emotional attention: A suitable measure in comparative studies? Psychonomic Bulletin and Review, 24(6), 1686-1717. https://doi.org/10.3758/s13423-0161224-1

Van't Riet, J., \& Ruiter, R. A. C. (2013). Defensive reactions to health-promoting information: An overview and implications for future research. Health Psychology Review, 7, 104-136. https://doi. org $/ 0.1080 / 17437199.2011 .606782$

Wagner, H. S., Howland, M., \& Mann, T. (2015). Effects of subtle and explicit health messages on food choice. Health Psychology, 34(1), 79-82. https://doi. org/10.1037/hea0000045

Watts, F. N., McKenna, F. P., Sharrock, R., \& Trezise, L. (1986). Colour naming of phobia-related words. British Journal of Psychology, 77(1), 97-108. https://doi. org/10.1111/j.2044-8295.1986.tb01985

Wiebe, D. J., \& Korbel, C. (2003). Defensive denial, affect, and the self-regulation of health threats. In L. D. Cameron \& H. Leventhal (Eds.), The self-regulation of 
health and illness behavior (pp. 184-203).

New York: Routledge.

Will, K. E., Sabo, C. S., \& Porter, B. E. (2009). Evaluation of the Boost 'em in the Back Seat Program: Using fear and efficacy to increase booster seat use. Accident Analysis and Prevention, 41(1), 57-65. https: / / doi.org/10.1016/j.aap.2008.09.007

Williams, J. M., Mathews, A., \& MacLeod, C. (1996). The emotional Stroop task and psychopathology. Psychological Bulletin, 120(1), 3-24. https://doi. org $/ 10.1037 / / 0033-2909.120 .1 .3$

Witte, K. (1992). Putting the fear back into fear appeals: The Extended Parallel Process Model. Communication Monographs, 59, 329-349. https://doi. org $/ 10.1080 / 03637759209376276$

Witte, K. (1994). Fear control and danger control: A test of the Extended Parallel Process Model. Communication Monographs, 61, 113-134. https://doi. org $/ 10.1080 / 03637759409376328$

Witte, K. (1998). Fear as motivator, fear as inhibitor: Using the Extended Parallel Process Model to explain fear appeal successes and failures. In P. A. Andersen \& L. K. Guerrero (Eds.), The handbook of communication and emotion research, theory, applications, and contexts (pp. 423450). San Diego, CA: Academic Press.

Witte, K., \& Allen, M. (2000). A meta-analysis of fear appeals: Implications for effective public health campaigns. Health Education and Behavior, 27, 591-616. https://doi. org $/ 10.1177 / 109019810002700506$

World Health Organization. (2003). WHO framework comvention on tobacco control. Geneva, Switzerland.

Xu, M., Li, Z., Diao, L., Zhang, L., Yuan, J., Ding, C., \& Yang, D. (2016). Social exclusion modulates priorities of attention allocation in cognitive control. Scientific Reports, 6, 31282. https://doi. org $/ 10.1038 /$ srep 31282

Yiend, J. (2010). The effects of emotion on attention: A review of attentional processing of emotional information. Cognition and Emotion, 24(1), 3-47. https://doi. org $/ 10.1080 / 02699930903205698$

Zimmerman, R. S., Cupp, P. K., Abadi, M., Donohew, R. L., Gray, C., Gordon, L., \& Grossl, A. B. (2014). The effects of framing and fear on ratings and impact of anti-marijuana PSAs. Substance Use and Misuse, 49(7), 824-835. https://doi.org/ $10.3109 / 10826084.2014 .880721$ 